\title{
A EDUCAÇÃO AMBIENTAL NA BASE NACIONAL COMUM CURRICULAR: OS RETROCESSOS NO ÂMBITO EDUCACIONAL
}

\author{
Adelson Dias de Oliveira ${ }^{1}$ \\ Alessandra Porto da Silva ${ }^{2}$ \\ Alexandre Junior de Souza Menezes ${ }^{3}$ \\ Luciana Pereira Camacam ${ }^{4}$ \\ Roseli Ramos de Oliveira ${ }^{5}$
}

Resumo: Este artigo propõe discutir a Educação Ambiental (EA) no contexto da Base Nacional Comum Curricular (BNCC). Tal documento, após a sua aprovação, passou a ser normativo e obrigatório para definição das aprendizagens comuns para a elaboração dos currículos de todas as escolas públicas e privadas do País. Portanto, o presente trabalho tem por objetivo analisar a inserção da temática ambiental dentro da última versão da BNCC, no âmbito da Educação Básica. Para tanto, foi realizada uma pesquisa nos documentos oficiais, artigos, reportagens, cuja análise e síntese imprimem a visão de um currículo mínimo, superficial, com redução e esvaziamento de conteúdos críticos, os quais aparecem de forma genérica, sem integralidade e tampouco transversalidade, constituindo retrocesso nas políticas em EA.

Palavras-chave: BNCC; Educação Ambiental; Esvaziamento; Reducionismo; Transversalidade.

1 Universidade do Estado da Bahia. E-mail: adelsonjovem@gmail.com, Link para o Lattes: http://lattes.cnpq.br/8640495876980514.

2Universidade de Araraquara (UNIARA). E-mail: elisporto1@hotmail.com, Link para o Lattes: http://lattes.cnpq.br/3364112221462270

${ }^{3}$ Universidade Federal do Vale do São Francisco, UNIVASF. E-mail: alexandrejuniorsm@hotmail.com, Link para o Lattes: http://lattes.cnpq.br/8868298636511416.

${ }^{4}$ Universidade Federal do Oeste da Bahia. E-mail: Iucamacam@yahoo.com.br. Link para o Lattes: http://lattes.cnpq.br/5324090786344858.

5 Universidade Estadual do Sudoeste da Bahia. E-mail: roseramos41@gmail.com, Link para o Lattes: http://lattes.cnpq.br/0134278968510619. 
Abstract: The referred article proposes to discuss Environmental Education (EA) in the context of the Common National Curricular Base (BNCC) which, after its approval, became a normative and mandatory document, which defines common learning for the elaboration of the curricula of all schools public and private sectors in the country. The present study aims to analyze the insertion of the theme within the latest version, from the perspective of Basic Education. To this end, research was carried out on the official documents, articles, reports, whose analysis and synthesis provide the vision of a minimal, superficial curriculum, with reduction and emptying of critical contents, which appear in a generic way, without integrality and neither transversality, constituting setback in EA policies.

Keywords: BNCC; Emptying; Environmental Education; Reductionism; Transversality.

\section{Introdução}

Acredita-se que estamos vivendo um momento de se buscar a "Educação Ambiental", isto é, uma educação que seja capaz de despertar a curiosidade, o prazer em criar, recriar e fazer com que pequenas atitudes no presente provoquem grandes colheitas no futuro.

A Educação Ambiental (EA) surgiu da necessidade de uma mudança de paradigma que envolve valores sociais, filosóficos, econômicos, éticos, ideológicos e científicos, adotados pela nossa sociedade. Dessa forma, a escola é corresponsável pela promoção dessas mudanças, juntamente com o poder público, por meio da legislação na área ambiental. Contudo, muitos desafios e demandas no campo educacional precisam ser superados, como por exemplo, uma formação adequada do(s) professor(res), definição do papel da escola na sociedade atual e melhor abordagem das questões ambientais dentro da Educação Ambiental no contexto escolar.

A presença da EA na educação básica, assim como na formação de professores (as), é mediada por uma série de documentos oficiais-Constituição Federal, Lei de Diretrizes e Bases da Educação, Parâmetros Curriculares Nacionais, Diretrizes Curriculares, Política Nacional do Meio Ambiente - tais instrumentos legais desempenham um papel relevante no desenvolvimento da EA no Brasil e sua ampla inserção nas práticas escolares.

Nessa perspectiva, com a aprovação da BNCC, intensificam-se as ações que promovem a padronização dos currículos das escolas públicas. Durante o processo de elaboração da BNCC e, até mesmo após a publicação da sua última versão, o documento tem gerado muitos debates e controvérsias por parte dos profissionais engajados no processo educacional. O projeto inicial da BNCC objetivava uma reforma da educação, entretanto, a proposta atualmente aprovada, trouxe mudanças, visto que parte da perspectiva capitalista, pautada por uma construção linear, vertical e centralizadora que direciona os interesses de aprendizagem para atender o mercado de trabalho, além de limitar a autonomia das escolas e, consequentemente, a atuação dos professores.

revista brasileira educação ambiental 
Diante da implementação da BNCC com essas características, algumas áreas como o ensino de Filosofia, de Sociologia, de Educação Física, de Artes e da Educação Ambiental perdem potencialidades, pois é mantida a proposta da Educação Ambiental de forma interdisciplinar e transversal, porém sem a obrigatoriedade, antes estabelecida no cenário educacional.

O presente trabalho tem como objetivo analisar a inserção da temática ambiental, para tanto, faz interface dessa temática com a BNCC, além de uma revisão sistemática de documentos como: Parâmetros Curriculares Nacionais, Diretrizes Curriculares Nacionais e Política Nacional do Meio Ambiente, os quais evidenciam que a abordagem da Educação Ambiental na BNCC atende aos interesses do mercado capitalista neoliberal, quando foca nas competências e habilidades que retiram a criticidade e a contextualização dos seus objetos/conteúdos de estudo e enfatiza um caráter prático, a fim de preparar o educando apenas para o mercado de trabalho instável, sem seguridade e excludente.

\section{Métodos}

O presente estudo adota como metodologia a pesquisa com abordagem qualitativa, utilizando-se do procedimento de pesquisa bibliográfica e documental. De acordo com Marconi e Lakatos (2007, p. 71), a abordagem qualitativa visa a "[...] colocar o pesquisador em contato direto com tudo o que foi escrito, dito ou filmado sobre determinado assunto, inclusive conferências seguidas de debates que tenham sido transcritos por alguma forma, quer publicadas, quer gravadas".

Foram acessados vídeos sobre debates da BNCC, dentre eles destacamse: seminários; rodas de conversas; formações de professores e eventos destinados à análise dos documentos norteadores, como as jornadas pedagógicas; além de audiências públicas realizadas em todo o Brasil, disponibilizadas na internet pelo governo Federal, com ênfase para as cinco últimas realizadas entre julho e setembro de 2017 (Ensino Fundamental), como também a última versão publicada em dezembro de 2018. Tais debates possibilitam obter um diagnóstico de como o processo de aprovação da BNCC transcorreu. Em síntese, este estudo está baseado em documentos, participações em reuniões e encontros no período de 2015 a 2018 que discutiram a Base Nacional Comum Curricular, de modo a permitir uma melhor análise do fenômeno pesquisado, bem como aprofundar as discussões desses documentos oficiais.

Também é um estudo comparativo que faz o cruzamento entre documentos como a Lei no 9.795, de 27 de abril de 1999, que institui a Política Nacional de Educação Ambiental (PNEA) e a Lei no 9.394, de 20 de dezembro de 1996, que estabelece a Lei de Diretrizes e Bases (LDB), a qual proporcionou um conhecimento significativo sobre o assunto. 
Além disso, foi realizada uma análise documental das políticas públicas de Educação Ambiental vigentes até 2020, das versões debatidas da BNCC, além de outros documentos oficiais como os Parâmetros curriculares nacionais (PCNs), Diretrizes Curriculares Nacionais para a Educação Ambiental (DCNEA) e Projetos Políticos Pedagógicos (PPP). Tais documentos norteiam o percurso educativo da EA na escola e auxiliam na tomada de decisões no sentido de fazer o que é correto para contemplar saberes e práticas docentes em consonância com o PPP - documento que norteia as diretrizes e consolida saberes e fazeres pedagógicos da unidade escolar que garantirá autonomia e direcionamento do trabalho sintetizador das práticas e pensamentos dos profissionais e da comunidade escolar, ele visa a retratar a identidade da instituição de ensino e se pauta no respeito das especificidades dos múltiplos sujeitos que compõem o coletivo da escola.

Foi realizada também uma revisão de literatura que buscou contemplar artigos publicados acerca da temática em tela imprescindível para a análise e constructos dos conhecimentos adquiridos a partir de documentos. Assim, esse universo literário possibilitou um entendimento significativo sobre o assunto que abordou a temática da $E A$, em que se destacaram autores que fazem alusão à Educação Ambiental como: Dias (2000), Guimarães (2004, 2006, 2007), Leff (2000, 2002, 2015), Reigota (1999, 2009), Carvalho (2002, 2006, 2008).

O estudo buscou analisar, mais especificamente por meio da análise comparativa, como Educação Ambiental está presente nos dois principais documentos curriculares: PCN e Base Nacional Comum Curricular, para verificar se houve avanços ou retrocessos na inserção da Educação Ambiental no ensino formal. Também buscou discutir se os documentos norteadores da Educação Básica apresentam semelhanças entre os documentos anteriores e a versão final da BNCC quanto às considerações relacionadas à preservação do meio ambiente.

\section{Uma síntese da trajetória da Educação Ambiental no Brasil sob as lentes dos documentos curriculares}

A questão da Educação Ambiental no Brasil começou a se concretizar principalmente a partir da década de 1980. Na Constituição federal de 1988, no Capítulo VI, art. 225, parágrafo. 1. Inciso VI, sobre o meio ambiente, é instituído como competência do poder público a necessidade de "promover a Educação Ambiental em todos os níveis de ensino" (BRASIL, 1988, on-line). A abertura dada à Educação Ambiental pela Constituição Federal vem favorecendo a sua institucionalização perante a sociedade brasileira, tanto que a atual Lei de Diretrizes e Bases da Educação Nacional determina que esta perspectiva de Educação seja considerada uma diretriz para os conteúdos curriculares da Educação Fundamental.

Desta forma, o Ministério da Educação (MEC) elaborou os Parâmetros Curriculares Nacionais (PCN) em que a Educação Ambiental é apresentada como 
tema transversal para todo o currículo, tratado de forma articulada entre as diversas áreas do conhecimento, de forma a impregnar toda a prática educativa e, ao mesmo tempo, criar uma visão global e abrangente da questão ambiental.

Segundo Novicki e Souza (2010), a temática ambiental está inserida no Brasil nos espaços formal e não formal de ensino e se faz notar tanto na Constituição Federal de 1988, quanto em outras esferas das políticas vinculadas à temática ambiental, como a Política Nacional de Meio Ambiente (PNMA) e a Política Nacional de Educação Ambiental (PNEA). No entanto, estritamente no que se refere ao ensino formal, existem hoje no Brasil três que abordam (ou deveriam abordar) a questão ambiental no currículo escolar: as Diretrizes Curriculares Nacionais (DCN), os Parâmetros Curriculares Nacionais (PCN) e a Base Nacional Comum Curricular (BNCC).

Em 1997, o Ministério do Meio Ambiente, o Ministério da Educação, o Ministério da Ciência e da Tecnologia e o Ministério da Cultura apresentaram, conjuntamente, o Programa Nacional de Educação Ambiental (PRONEA), revisado por consulta pública em 2005, que busca, por meio de seus princípios e linhas de ações propostos, intensificar a implantação da Educação Ambiental na sociedade nacional.

Em 1999, é outorgada a Política Nacional de Educação Ambiental, a qual expõe, no Art. $2^{\circ}$, que "A Educação Ambiental é um componente essencial e permanente da educação nacional, devendo estar presente, de forma articulada, em todos os níveis e modalidades do processo educativo, em caráter formal e não formal". Ao longo dos anos 2000, o Ministério do Meio Ambiente vem implantando - Sistema Brasileiro de Informações sobre Educação Ambiental e Práticas Sustentáveis (SIBEA); a formação de coletivos educadores; Municípios Sustentáveis e seus educadores ambientais populares. No MEC, o "Vamos cuidar do Brasil com as escolas"; a formação das Com-vidas nas escolas; as Conferências de Meio Ambiente promovidas pelo órgão gestor do ProNEA, entre outras iniciativas institucionais.

Percebe-se, assim, que a Educação Ambiental já é uma realidade, dadas as políticas públicas que estão sendo traçadas. Contudo, é necessário que esta institucionalização seja acompanhada por um aprofundamento crítico nas discussões por parte dos educadores em seu cotidiano e da sociedade em geral, para que essa se efetive como uma prática social que possibilite o enfrentamento da grave crise socioambiental. Portanto, Educação Ambiental é uma reflexão necessária.

\section{A Educação Ambiental no Brasil e os estudos dos marcos legais}

A partir da década de 1980 vários esforços foram direcionados com o objetivo de minimizar os problemas ambientais e incentivar a participação social. Esse momento marca a história brasileira com alguns acontecimentos: movimentos sociais, participação da sociedade civil, debate de questões ecológicas, entre outros. Os movimentos ambientais caracterizam-se pela 
diversidade de suas motivações, seus interesses e ações transcendendo uma classificação ou vinculação partidária (LEFF, 2015, p. 111).

Ao longo dessa trajetória, surge a Constituição Federal de 1988, comprometida com a igualdade de oportunidades e a redução das desigualdades socioeconômicas. O impacto dessa diretriz se desdobrou em ações como; a Rio-92, a Política Nacional do Meio Ambiente (PNMA), seguidas da PNEA, Lei $n^{\circ} 9.795 / 1999$, posteriormente regulamentada pelo Decreto $n^{\circ}$ 4.281/2002 o que vem a consolidar a PNEA (BRASIL, 2017). Esses instrumentos legais foram determinantes para a consolidação dos princípios, objetivos e diretrizes da $E A$, em consonância com documentos pactuados pela sociedade civil, como o Tratado de Educação Ambiental para Sociedades Sustentáveis e Responsabilidade Global e a Carta da Terra (BRASIL, 2017).

Assim, a Educação Ambiental ganhou notoriedade com a promulgação da Lei 9.795, de 27 de abril de 1999, que instituiu uma Política Nacional de Educação Ambiental e, por meio dela, foi estabelecida a obrigatoriedade da Educação Ambiental em todos os níveis do ensino formal da educação brasileira. A lei 9.765/1999 precisa ser mencionada como um marco importante da história da Educação Ambiental no Brasil, porque ela resultou de um longo processo de interlocução entre ambientalistas, educadores e governos (BRASIL, 1999).

Pela emergência da EA no contexto das escolas de Educação básica, respaldamos nosso entendimento na Lei no 9.795/1999 que institui a Política Nacional de Educação Ambiental (PNEA) e indica que a EA é um componente essencial, permanente e duradouro da educação nacional, devendo estar presente em todos os níveis da Educação básica, assim como na educação superior, educação especial, profissional e na educação de jovens e adultos.

A Educação Ambiental é uma dimensão da educação, por isso deve ser uma atividade intencional da prática social, que promova o desenvolvimento individual pautado por um caráter social em sua relação com a natureza e com os outros seres humanos, de modo que potencialize essa atividade humana com a finalidade de torná-la plena de prática social e de ética ambiental (BRASIL, 2012, p. 2).

Diante do exposto, os conhecimentos acerca da EA devem ser inseridos nos currículos da Educação básica e da educação superior pela transversalidade, conforme consta no artigo 16 das Diretrizes Curriculares Nacionais para a Educação Ambiental (DCNEA), "mediante temas relacionados com o meio ambiente e a sustentabilidade socioambiental" (BRASIL, 2012, p. 5).

As Diretrizes Curriculares Nacionais para a Educação Ambiental (DCNEA) foram aprovadas e homologadas em junho de 2012 e constituem um documento de mais de 500 páginas que atende uma exigência constitucional (artigos 22 e 210) que afirmam que: 
compete privativamente à União legislar sobre [...] diretrizes e bases da educação nacional" e prevê que "serão fixados conteúdos mínimos para o ensino fundamental, de maneira a assegurar formação básica comum e respeito aos valores culturais e artísticos, nacionais e regionais (BRASIL, 2013, online).

Dessa forma, destacamos a importância da Educação Ambiental na perspectiva de uma educação cidadã que corrobore a integração entre as pessoas e o meio em que estão inseridas, de modo que seja fortalecida a responsabilidade social

No que diz respeito ao Projeto Político Pedagógico das escolas, as DCNs o definem como elemento constitutivo para a operacionalização da Educação Básica. Segundo o art. 44, da Resolução CNE/CEB n 4/2010, o Projeto Político Pedagógico, instância de construção coletiva que respeita os sujeitos das aprendizagens, entendidos como cidadãos com direitos à proteção e à participação social, deve contemplar: estudo e desenvolvimento de atividades socioambientais, conduzindo a Educação Ambiental como uma prática educativa integrada, contínua e permanente (BRASIL, 2013).

Os PCNs foram lançados pelo MEC entre os anos de 1997 e 1999, a fim de se tornarem uma referência curricular para os professores de todo o país, que podem adaptá-los às realidades de sua região ou município. A primeira parte do arquivo dos PCN, que aborda o Tema Transversal Meio Ambiente, lembra muito as Diretrizes Curriculares Nacionais, pois aborda brevemente a crise ambiental em que o mundo passa atualmente, as preocupações que devem ser tomadas em relação ao Meio Ambiente, e a busca por novos valores e atitudes de todos. Em outro trecho, o documento aborda alguns pontos polêmicos relacionados ao debate ambiental, tentando desmistificar alguns pontos que podem trazer empecilhos na defesa do meio ambiente.

Outra parte do documento em questão refere-se em ensinar e aprender Educação Ambiental, que contribuem para a formação de cidadãos conscientes. Com isso, mostra que tais atitudes são necessárias e devem estar presentes no cotidiano escolar por meio de projetos, inserção do tema dentro das disciplinas, para o desenvolvimento de uma postura crítica do aluno. Os PCN também apontam a necessidade de se trabalhar a Educação Ambiental de modo transversal, assim cada professor deve abordar a questão ambiental, adequando-se ao seu conteúdo dentro de sua área, a fim de deixar claro e objetivo os valores que devem ser transmitidos. Em sua última parte, os PCNs apresentam os conteúdos e critérios adotados e como os temas devem ser tratados para atingir o objetivo desejado.

Desse modo, os documentos pesquisados de forma consensual, apresentada por meio dos PNEA, DCNs, PCNs, compartilham do mesmo entendimento, ou seja, que a EA nas escolas deve ser desenvolvida 
conforme os nexos da transversalidade e da interdisciplinaridade. No entanto, o governo federal propôs, entre 2017 e 2018, uma reformulação tanto no ensino fundamental quanto no médio, de modo a implantar uma nova Base Nacional Curricular Comum (BNCC), na qual os temas transversais (a Educação Ambiental, inclusive) não estão contemplados de maneira explícita.

\section{Educação Ambiental na Base Nacional Comum Curricular}

A proposta de elaboração de um currículo nacional não é recente, é um processo histórico das políticas educacionais, na direção de que a BNCC seja referência curricular em nível nacional, com objetivo de estabelecer conteúdos mínimos para Educação básica. Para tanto, deve nortear os currículos e as propostas pedagógicas das escolas públicas e privadas em todo Brasil (BRASIL, 2010). Essa iniciativa já era prevista na Constituição de 1988, na LDB (Lei №. 9394/1996) e no Plano Nacional de Educação (PNE) de 2014.

A Base Nacional Comum Curricular é um documento oficial que define direitos, objetivos de aprendizagem e desenvolvimento que orientarão a elaboração dos currículos nacionais. Assim, o documento preconiza objetivos que devem percorrer as etapas de parte da Educação Básica (BRASIL, 2017).

A BNCC se materializou em 2017, aprovada pelo Conselho Nacional de Educação (CNE), consolidando-se com a proposta do estabelecimento de uma Base Nacional que tomou o lugar de uma concepção de Base Comum Nacional, conceito construído pelo movimento dos educadores ao longo das lutas por uma educação cidadã. Atualmente, a BNCC tem sido o carro-chefe das políticas educacionais desenhadas pelo Ministério da Educação, especialmente após o impeachment da Presidenta eleita Dilma Rousseff que impacta de forma direta nas políticas direcionadas aos currículos escolares, à formação dos profissionais de educação, bem como os processos avaliativos nas escolas e sistemas de ensino.

Em relação às alterações dos currículos das escolas públicas e privadas, destacamos a entrevista de Frigotto, realizada por Dickmann, Frigotto e Pertuzatti (2017). Nesta oportunidade, Frigotto foi questionado sobre o seu posicionamento acerca da BNCC, segundo ele, é uma base pelo avesso, pois "o teor é conservador, é restritivo e é penalizador, uma vez mais, da escola pública. Essas bases são para a escola pública, a escola privada faz o que quer e não vai fazer isto; lá vai ter tudo isto que se nega, então, esse para mim é o eixo do debate" (DICKMANN; FRIGOTTO; PERTUZATTI, 2017, p. 877).

Concordamos com as palavras de Frigotto e destacamos que a elaboração de uma BNCC, em nível nacional, gera impactos em diferentes segmentos do campo educacional, a saber: na formação de professores, na elaboração dos materiais didáticos e nas avaliações educacionais. Acreditamos que tais impactos não são garantias de avanços na educação, ao contrário, demostram retrocesso histórico, bem como a centralização e a homogeneização do complexo processo educacional brasileiro. 
Respaldada na Constituição Federal, na Lei de Diretrizes e Bases e na referência a modelos de ensino de outros países, a ênfase já não é apenas indicar os direitos de aprendizagem, mas estabelecer, para as habilidades, quais objetos de conhecimento deveriam ser contemplados conforme as práticas de linguagem, os campos de atuação e o ano escolar, a exemplo da última versão, aspecto que amplia cada vez mais a precarização do trabalho docente.

Diante deste contexto, vivemos um tempo em que as áreas de conhecimentos da EA estão sendo silenciadas, como mostra o negligenciamento das produções teórico-metodológicas desses campos em documentos oficiais, como a BNCC (SILVA; EL-HANI, 2014, OLIVEIRA; NEIMAN, 2020). Vê-se também o sucateamento e o desmantelamento da ciência, devido aos cortes e contingenciamentos de recursos de instituições de fomento à pesquisa, além da precarização das escolas e universidades públicas.

Nessa perspectiva, compreendemos a importância da reflexão sobre a abordagem da Educação Ambiental como papel preponderante de conduzir a novas iniciativas, de desenvolver novos pensamentos e práticas que possam formar cidadãos conscientes e participativos das decisões coletivas. Além disso, seu papel não se reduz ao meio ambiente, mas seu leque se amplia para a economia, a justiça, a qualidade de vida, a cidadania e a igualdade.

Obviamente, é nesse viés que há um nexo entre a EA e a BNCC, a qual vem sendo questionada desde as versões anteriores nos trabalhos de Andrade e Piccinini (2017), Santinelo, Royer e Zanatta (2016), Oliveira e Neiman (2020) e Wutzki e Tonso (2017). É uma unanimidade entre os referidos autores que as versões da BNCC não abordam a EA de forma crítica e com profundidade sobre as abordagens socioambientais. O que leva a um total silenciamento do que é discutido e produzido pelo campo, no Brasil.

\section{A cenarização da Educação Ambiental sob o olhar da Prática Docente}

A discussão sobre EA apresentada no ambiente escolar deve favorecer maior conhecimento sobre a temática e ser mediada por profissionais com conhecimento do tema. Dessa forma, é possível que haja um novo repensar dos saberes que fomentem uma proposta educativa eficiente e ética. Para tanto, essa pesquisa se justifica por abordar uma discussão atual norteada pela investigação da EA no âmbito formal, para tanto considera os marcos legais que regulamentam a aplicabilidade e o desenvolvimento desse percurso no ensino fundamental II e as implicações desse descumprimento na esfera educacional.

Segundo os Parâmetros Curriculares Nacionais (PCN), de 1997, os professores devem trabalhar a Educação Ambiental de forma transversal e interdisciplinar permeando todas as disciplinas presentes no currículo escolar para que os alunos possam entender sua complexidade. Nesse aspecto, Morin (2001), salienta que os professores não devem prender-se em sua disciplina, mas devem trabalhar de forma conjunta e holística. 
Nesse entendimento, Carvalho (2006), destaca que a EA deverá ser uma das prioridades no curso de formação de professores, pois o futuro do planeta depende das ações que são tomadas pelo homem. Portanto, caso os docentes não tenham conhecimento da importância desse tema, fica difícil inseri-la na sua prática pedagógica, visto que a prioridade fica apenas para os assuntos específicos de sua disciplina. Assim, não conseguirão realizar atividades de forma interdisciplinar, conforme sugerem os PCN sobre meio ambiente.

Kindel (2012) frisa que as práticas pedagógicas, realizadas pelos professores em sala de aula, devem fazer com que os alunos se posicionem de forma crítica perante os problemas ambientais que são trabalhados pelo professor durante a realização das atividades. O docente deve proporcionar aos alunos uma aprendizagem significativa e relacionada com as experiências vividas por eles, além de serem problematizadores que facilitarão a relação educando e objeto de conhecimento, uma vez que assim conseguirá preparar o aluno para tomar iniciativas e ser um agente transformador. Desse modo, entende-se que os docentes devem buscar práticas e metodologias que auxiliem no desafio relacionado ao trabalho de promoção da aprendizagem. Tal prática deve considerar recursos necessários ao processo educativo que promovam a condição humana de um repensar sobre as perspectivas atuais da educação e da educação do futuro.

Para Gatti (2015), o processo que envolve o ensino tem vários desafios, entre eles se destacam as políticas em educação e, em particular, as questões da formação dos docentes. Desse modo, é de grande relevância que haja uma política nacional que fomente a formação de professores que qualifique as suas práticas e saberes com a intencionalidade de desenvolverem um novo pensamento e novas experiências no campo pedagógico.

\section{Conclusões}

A Educação Ambiental tem o papel de formar uma prática educacional sincronizada e sintonizada com a vida em sociedade, ou seja, uma percepção mais humanizadora que busque, mediante apostas metodológicas, informar e estimular a percepção dos educadores ambientais, profissionais e pessoas, de modo a sensibilizá-los para participar de ações, por meio das quais, em um exercício pleno de cidadania, possam encontrar soluções sustentáveis que assegurem a manutenção e a elevação da qualidade de vida.

Conforme Santinelo, Royer e Zanatta (2016, p.1), "a necessidade em promover a EA é um consenso social; preocupações com a manutenção da vida do nosso planeta nunca foram tão expressivas e necessárias". Contudo, esse aparente consenso é ignorado na BNCC. Ainda que as contrarreformas educacionais atuais sejam anunciadas no sentido de promover consensos entre a opinião pública - como a necessidade de educação de qualidade, crítica e reflexiva, que levará à equidade - ao nos desprendermos das aparências e nos dedicarmos à análise de sua essência, podemos perceber que, em sua 
materialidade, a proposta de centralização curricular contradiz o que se espera alcançar com a EA.

Observamos que a tendência de ocultamento da EA foi evidenciada por pesquisas realizadas sobre o espaço do tema nas versões preliminares e na versão final da BNCC. Verificamos também que a EA é citada na BNCC uma única vez, na introdução do documento, em que é especificada a relação da BNCC com o currículo. Nesse contexto, a Educação Ambiental é reduzida ao que deve ser incorporado ao currículo e às propostas pedagógicas. A última versão da BNCC, marcada pelo esvaziamento da EA com teor crítico, contribui para a produção de um texto que não apresenta as ligações histórico, social, cultural que materializam os problemas ambientais.

Consideramos que a ambiência escolar tem várias lacunas a serem superadas, as quais se constituem um desafio para a operacionalização e solidificação no campo da BNCC. A interpretação dos eixos norteadores e integradores nos currículos é basilar, pois eles tratam dos conhecimentos essenciais para o aluno.

Outra preocupação está centrada na adequação à realidade da escola e dos alunos, mas isso só será possível com o fortalecimento do PPP, o qual, em sua plenitude, garante maior autonomia e reestabelecimento das práticas educativas. Entretanto, cabe discutir acerca dos espaços da autonomia e seu comprometimento com as determinações legais, instrumentos esses determinados pela lei, decretos e portarias que determinam a aplicabilidade necessária para o pleno desenvolvimento do processo educacional.

Por fim, na restruturação curricular, conforme os moldes da BNCC, é mister fugir de práticas educacionais reducionistas, fragmentadas e de uma abordagem ineficaz, descontínua e de efemeridade. Desse modo, o ponto crucial se centra na concepção docente, cuja abordagem deve consistir na práxis pedagógica bem estruturada, sustentada no planejamento, na ressignificação no repensar das novas práticas, na adoção de estratégias didáticas pautadas na aplicabilidade das metodologias ativas no ato pedagógico.

Assim, a formação continuada, articulada e integradora deverá despertar expectativas de consolidação de estudos e desenvolvimento de atividades socioambientais, além de conduzir a Educação Ambiental como prática de proteção, de cuidado, de participação social frentes às questões da contemporaneidade e de garantias sustentáveis para as gerações presentes e futuras.

\section{Referências}

ANDRADE, M.C.P.; PICCININI, C.L. Educação Ambiental na Base Nacional Comum Curricular: retrocessos e contradições e o apagamento do debate socioambiental. Anais do IX Encontro Pesquisa em Educação Ambiental. Universidade Federal de Juiz de Fora, 2017.

BRASIL, Ministério da Educação. A Base Nacional Comum Curricular Introdução. Brasília: MEC. 2017b. 
BRASIL, Ministério da Educação. A Base Nacional Comum Curricular Apresentação. Brasília: MEC. 2017c.

BRASIL, Ministério da Educação. A Base Nacional Comum Curricular - A Estrutura da BNCC. Brasília: MEC. 2017e.

BRASIL, Ministério da Educação. A Base Nacional Comum Curricular - A Etapa do Ensino Fundamental. Brasília: MEC. 2017g.

BRASIL, Ministério da Educação. Base Nacional Comum Curricular Perguntas Frequentes. Brasília: MEC. 2017a.

BRASIL, Ministério da Educação. Base Nacional Comum Curricular - Ensino Médio. Brasília: MEC. 2018a.

BRASIL, Ministério da Educação. Etapa do Ensino Médio é homologada e Base Nacional Comum Curricular está completa. Brasília: MEC. 2018b.

BRASIL, Ministério da Educação. Novo Ensino Médio - Dúvidas. Brasília: MEC. $2017 f$.

BRASIL, Ministério da Educação. Os relatórios analíticos e pareceres relativos à segunda versão podem ser consultados no site. Base Nacional Comum Curricular. Brasília: MEC, 2017d.

BRASIL. Base Nacional Comum Curricular (BNCC). Educação é a Base. Brasília, MEC/CONSED/ UNDIME, 2017.

BRASIL. Constituição da República Federativa do Brasil, 1988. Brasília: Senado Federal, Centro Gráfico, 1988.

BRASIL. Diretrizes Curriculares Nacionais da Educação Básica. Disponível em: <http://portal.mec.gov.br/index.php?option=com docman\&view=download \&alias=13448-diretrizes-curiculares-nacionais-2013-pdf\&ltemid=30192>.

Acesso em: 2 fev. 2017.

BRASIL. Diretrizes Curriculares Nacionais para a Educação Ambiental, Brasília, 2012. Disponível em:<http://portal.mec.gov.br/conselho-nacional-deeducacao > Acesso em: 8 set. 2020.

BRASIL. Educação Ambiental: aprendizes de sustentabilidade. Secretaria de Educação Continuada, Alfabetização e Diversidade. Ministério da Educação. Secretaria de Educação Continuada, Alfabetização e Diversidade (Secad/MEC), Brasília - DF, mar. 2007.

BRASIL. Lei no 13.005, de 25 de junho de 2014. Aprova o Plano Nacional de Educação - PNE e dá outras providências. Diário Oficial da União, Brasília, 26 de junho de 2014.

BRASIL. Lei № 9.394, de 20 de dezembro de 1996.Estabelece as Diretrizes e Bases da Educação Nacional (LDB) Disponível em <http://www.planalto.gov.br/ccivil 03/Leis/L9394.htm>. Acesso em: 15 set. 2020.

BRASIL. Lei no 9.795, de 27 de abril de 1999.Política Nacional de Educação Ambiental. Brasília-DF. Disponível em: $<$ http://www.planalto.gov.br/ccivil 03/leis/19.795.htm>. Acesso em: 16 agosto. 2020. 
BRASIL. Lei número 9.795 de 27 de abril de 1999. Política Nacional de Educação Ambiental, Diário Oficial da União, Brasília, 1999.

BRASIL. Ministério de Educação. Parâmetros Curriculares Nacionais.1997, Disponível em: <http://portal.mec.gov.br/seb/arquivos/pdf/livro01.pdf>. Acessado em: 5set. 2020.

BRASIL. Ministério do Meio Ambiente. Programa Nacional de Educação Ambiental Disponível em: $<$ http://www.mma.gov.br/estruturas/educamb/ arquivos/pronea3.pdfpg33>.

Acessado em: 4 set. 2020.

BRASIL. Resolução no 2, de 15 de junho de 2012. Estabelece as Diretrizes Curriculares Nacionais para a Educação Ambiental. Disponível em: $<$ http://portal.mec.gov.br/index.php?option=com docman\&view=download\&alia $\mathrm{S}=10988$-rcp002-12-pdf\&category slug=maio-2012-pdf\&ltemid=30192>

Acessado em: 3 agosto 2020.

BRASIL. Secretaria de Educação Fundamental. Parâmetros Curriculares Nacionais: apresentação dos temas transversais/ Secretaria de Educação Fundamental. Brasília: MEC/SEF, 1997.

BRASIL. Secretaria de Educação. Parâmetros Curriculares Nacionais: Temas Transversais. Brasília: MEC/SEF, 1997.

CARVALHO, I. C. M. Educação Ambiental: a formação do sujeito ecológico. 2. ed. São Paulo: Cortez, 2006.

CARVALHO, I.C.M. O "ambiental" como valor substantivo: uma reflexão sobre a identidade da Educação Ambiental. Textos escolhidos em Educação Ambiental: de uma América à outra. Montreal: Publications ERE-UQAM, v. 1, 2002.

CARVALHO, V.S. Educação Ambiental urbana. Rio de Janeiro: Wak Ed, 2008.

DIAS, G.F. et al. Educação Ambiental: Princípios e práticas. 6ª Edição. São Paulo: Editora Gaia, 2000.

DICKMANN. I.; FRIGOTTO, G.; PERTUZATTI, I. Currículo integrado, Ensino Médio Técnico e Base Nacional Comum Curricular: Entrevista com Gaudêncio Frigotto. Revista e-Curriculum. v. 15, n.3, p. 871 2017. Disponível em: $<$ https://revistas.pucsp.br/index.php/curriculum/article/view/30272>. Acesso em: 16 ago. 2020.

GATTI, B. A. Políticas educacionais e educação básica: desafios para as políticas e formação docente. In: PACHECO RIOS, J. A. V. (Org.). Políticas, práticas e formação na educação básica. Salvador: Editora da UFBA, 2015. p. 25-34.

GUIMARÃES, M. A Formação de Educadores Ambientais. Campinas: Papirus, 2004.

GUIMARÃES, M. Armadilha paradigmática na Educação Ambiental. Pensamento complexo, dialética e Educação Ambiental. São Paulo: Cortez, v. 1, p. 15-29, 2006. 
GUIMARÃES, M. Educação Ambiental: no consenso um embate? Papirus Editora, 2007.

KINDEL. E.A.I. Práticas Pedagógicas em Ciências: espaço, tempo e corporeidade. Erechim: Edelbra, 2012.

LEFF, E. Ecologia, capital e cultura: racionalidade ambiental, democracia participativa e desenvolvimento sustentável. Tradução Jorge Esteves da Silva. Blumenau: EDIFURB, 2000.

LEFF, E. Epistemologia Ambiental. Tradução Sandra Valenzuela. 2. ed. São Paulo: Cortez, 2002.

LEFF, E. Saber ambiental: sustentabilidade, racionalidade, complexidade, poder. Tradução Lúcia Mathilde. 11. ed. Petrópolis: Vozes, 2015.

MARCONI, M.A.; LAKATOS, E.M. Metodologia cientifica: ciência e conhecimento científico, métodos científicos, teoria, hipóteses e variáveis. 5. ed. São Paulo: Atlas, 2007.

MORIN, E. (2001). Os sete saberes necessários a educação do futuro. São Paulo: Cortez

NOVICKI, V.; SOUZA, D.B. Políticas públicas de Educação Ambiental e a atuação dos conselhos de meio ambiente no Brasil: perspectivas e desafios. Ensaio: aval.pol.públ.Educ. vol.18 no.69 Rio de Janeiro Oct./Dec. 2010.

OLIVEIRA, L.; NEIMAN, Z. Educação Ambiental no Âmbito Escolar: Análise do Processo de Elaboração e Aprovação da Base Nacional Comum Curricular (BNCC). Revista Brasileira de Educação Ambiental, v.15, n 3, p.36-52, 2020. REIGOTA, M. O que é Educação Ambiental. rev. São Paulo: Brasiliense, 2009. REIGOTA, M. O que é Educação Ambiental. São Paulo: Brasiliense, 2012. Coleção Primeiros Passos, v. 292, 1999.

SANTINELO, P. C. C.; ROYER, M. R.; ZANATTA, S. C. A Educação Ambiental no Contexto Preliminar da Base Nacional Comum Curricular. Pedagogia. Foco, Iturama (MG), v. 11, n. 6, p. 104-115, 2016.

SILVA, S. N.; EL-HANI, C. N. A abordagem do tema ambiente e a formação do cidadão socioambientalmente responsável. Revista Brasileira de Pesquisa em Educação em Ciências, Belo Horizonte, v. 14, n. 2, p. 225-234, 2014.

WUTZKI, N. C.; TONSO, S. A Educação Ambiental e a $2^{a}$ versão preliminar da base nacional curricular comum (BNCC): uma reflexão sobre a área de ciências da natureza. In: Encontro Nacional de Pesquisa em Educação em Ciências, 11. 2017, Florianópolis. Anais [...]. Florianópolis: UFSC, 2017. p. 1-9. 